\title{
Natural Languages vs Languages of Augmented Reality
}

\author{
Olena Panchenko ${ }^{1}$, Anastasiia Plakhtii ${ }^{2, *}$, Yevhen Plakhtii ${ }^{1}$ \\ ${ }^{1}$ Oles Honchar Dnipro National University, Ukraine \\ ${ }^{2}$ Prydniprovska State Academy of Civil Engineering and Architecture, Ukraine \\ *Corresponding author.Email: anastasia@bukreyev.com
}

\begin{abstract}
The article deals with the problem of mutual interaction of natural languages and the artificial languages which appear in augmented reality. The artificial languages which have recently appeared are creolized linguistic units, leet, LOL, texting, programming languages etc. Their origin is connected with natural language but then they change themselves and change natural languages. The main tendencies of these changes are a wide usage of shortenings, breaking the spelling rules, addition of sound support etc. as a result a natural language has got a new form keeping the same meanings.
\end{abstract}

Keywords: language, natural language, artificial language, compression, augmented reality.

\section{INTRODUCTION}

A language is a phenomenon which is present in all types of realities and it has been constantly changing. In a rapidly changing society where there is a great deal of available information and knowledge, adopting and applying information at the right time and right place is needed to main efficiency in both learning and business settings. The augmented reality (AR) is one technology that dramatically shifts the location and timing of education and training. It is a technology which provides real time integration of digital content with the information available in real world, it enables direct access to implicit information attached with context in real time. Augmented reality enhances our perception of real world by enriching what we see, feel, and hear in the real environment. It has a great influence on the natural language and now it has intermixed with a number of artificial new communication creations: creolized text, LOL etc. This paper deals with the description of mutual influences of such languages. We can suggest that this period of language changes under the influence of new technologies is not the first one in history, for example the appearance of printed mass-media also led to the appearance of various means of linguistic compression. The physical space of locating the linguistic units is lessening but this space is augmented by various technologies, thus changing the character of corresponding linguistic units.
The aim of the paper is to compare natural and artificial languages of augmented reality and to analyze the main mutual changes.

Methods. Descriptive research model was used in this study. This method helped to describe the existing situation as it was. As the first step of our research we have used the analysis of the key scientific papers dealing with our problem. The research stage included comparative method concerning a natural language (English in our case) and new languages of augmented reality as well. This research seeks the answer to the question: Does the language improve?

\section{LITERATURE REVIEW}

The papers which are the theoretical basis of our article belong to two groups: the works concerning teaching languages in conditions of augmented reality and the works concerning language formation of today, mainly the language of programming. Some methodological positions of these papers are used by us, but the languages of programming are not included into the material of our research.

To begin with, we are to define the notion of augmented reality itself. According to Klopfer and Squire [1], AR is "a situation in which a real world context is dynamically overlaid with coherent location or context sensitive virtual information" [1]. In this situation, AR could provide users technology- 
mediated immersive experiences in which real and virtual worlds are blended [2] and users' interactions and engagement are augmented [3],[4]. The process of combining virtual data with real-world data can provide users with access to rich and meaningful multimedia content that is contextually relevant and can be easily and immediately acted upon [5].

In the field of language education, written and oral comprehensible input are vital for learners, because using pictures, videos, sounds and animations enrich the input and make the learning long lasting, interesting [6] and promotes enhanced learning achievement [7], [8], [9]. Staying for a longer time in the community where the target language is spoken is the one of the most effective ways of learning a foreign language. However, time and financial limitations prevent learners to follow this way. In this case, AR technology offers this opportunity and brings the reallife objects into the language classroom and creates a feeling of authenticity. Di Serio [8] investigated the role of augmented reality technology in motivating middle school students for a visual art course in Spain. They introduced the lesson in two different formats as slide-based and augmented reality technology-based environment. Then, they administered the Instructional Materials Motivation Survey to participants to collect data about their motivational level. The results of the study revealed that participants rated higher the motivational factors of attention and satisfaction in an augmented-realitybased learning environment than slide-based learning environment. When factors were analyzed separately, the attention and confidence were factors which had the highest mean. Finally, this study suggested that augmented reality technology had a positive impact on the motivation of middle-school students.

Augmented reality is aimed to intensely transform present education as we know it. The capacity to overlay rich media onto the real world for viewing through web-enabled devices such as phones and tablet devices means that information may be available to students at any time and place. The use of AR technology particularly in language classroom will provide richer learning environment which is one of the essentials of language learning [10], [11], [12], [13]. As this technological tool offers many input channels such as sound, animation, pictures, it will make learning more productive, effective, interesting and faster [6]. Wireless mobile devices, such as smart phones, tablet PCs, and other electronic innovations, are increasingly ushering AR into the mobile space where applications offer a great deal of promise. The affordances of mobility enable activities that leverage the authenticity of real-world environments and live social interactions with other participants. Within these mobile AR simulations, students primarily interact with each other and with the real environment around them. This experience is augmented with information that is accessed periodically from location-based simulations that run on personal digital assistants or cell phones [14], [15].

Then how can AR technologies be used for educational purposes? First, AR technologies help learners engage in authentic exploration in the real world, and virtual objects such as texts, videos, and pictures are supplementary elements for learners to conduct investigations of the real-world surroundings [16]. One of the most prevalent uses of AR is to annotate existing spaces with an overlay of locationbased information [3]. Secondly, the use of AR technologies can extend to the integration of realworld and digital learning resources. As Klopfer and Squire [1] showed, the usage of AR enables learners to experience scientific phenomena that are not possible in the real world (e.g., chemical reactions). Through explorations in AR, students were able to view the virtual solar system on the classroom table or to visualize the process of photosynthesis.

One of the main papers of the first direction is that written by Godwin-Jones [17] based on the role of Pokemon-GO, which is the first mobile augmented reality game to reach the top of the download charts of mobile applications. It focused public attention on augmented reality. As always occurs with newly popular uses of technology, the education community soon started to explore how to use the game in teaching and learning. Though Pokemon-GO was not designed for language learning and many of the ways in which language teachers have enlisted the playing of the game in the service of learning could apply to other commercial mobile games. Through its ability to use add-on digital assets to explore and expand scenes and locales from the real world, there is an obvious connection between AR and current theories of second language acquisition which emphasize localized, contextual learning and meaningful connections to the real world. In fact, AR has been in use for some time in language learning applications. These games offer a new take on technology-enabled learning: the technology supports explorations and learning situated in the students' natural context: their own community and surroundings. The power in AR, which sets it apart from traditional curricula and even from purely virtual learning environments, lies in truly augmenting the physical landscape, using digital technologies to enable students to see the world around them in new ways. 
Godwin-Jones says there is an obvious connection between AR and current theories of second language acquisition which emphasize localized, contextual learning and meaningful connections to the real world. We consider that it concerns teaching any language [17]. The researcher considers this possibility using mobile games created using the ARIS platform (AR and Interactive Storytelling), a free open source game editor of the University of Wisconsin. From his point of view, there are various ways for teachers to use the AR, because it is advisable to study the language in connection with expanded digital spaces. Augmented reality allows the user to perceive the real world through a virtual overlay. Virtual objects used in augmented reality systems may include text, images, video clips, sounds, 3D models and animations. Ideally, these virtual objects will be perceived as coexisting within a real-world environment. A number of researchers have identified that augmented reality as having immense potential to enhance learning and teaching. Results of studies by Bower, Howe, McCredie, Robinson, and Grover [18] and Slussareff and Boha'c 'kova' [19] and others [20], [21] confirm the positive learning outcomes of student-generated AR. Students can be involved in both creating markers, by capturing images on their mobile devices [17].

Long-term, AR can be a valuable tool for travelers interested in learning through real-world immersion in a culture, regardless of language barriers. AR can be used today for traditional language learning, if we can still call it that. Augmented reality experiences can take a variety of forms. Smartphone-based AR applications allow users to travel through their environment while looking at their augmented world through a mobile device, but the mobile device limits the user's ability to physically interact with the augmented space. Webcam-based AR applications make use of a computer camera to capture a physical space and display an augmentation on a screen, such as a desktop monitor, allowing the user to use their hands to easily manipulate the augmented content.

Augmented reality can also help tourist organizations and travel agencies on reaching wider audiences by being a tool of technology that has an appealing multimedia content. AR information systems can help tourists in knowing the essential information and enhancing their knowledge about a tourist attraction, while in the same time, increasing the experience and having entertainment throughout the process. An example of this is developed by Lonely Planet - Compass City Guides. It is an Android application wherein expert advices about 25 cities around the world - some of these cities are
Amsterdam, Bangkok, Boston, Istanbul, Seoul, Singapore, Sydney, and Tokyo - are available and is equipped with GPS-enabled maps and AR camera views [22].

Ruth Valle underlines that teaching with Augmented Reality makes him feel that he is on the cutting edge of educational technology. His students are excited to come to class to see what they will do and discover next [23].

Yeh and Kessler [21] state that their purpose is to explore the role of global literacy in academic settings as the effect of increasingly digital technologies is being felt across areas of teaching and learning. Digital, global democracies require global literacy skills of individuals for twenty-first century citizenship and intercultural and linguistic competencies. The paper covers such issues as the enhancement of global literacy through linguistic and intercultural competencies; the use of technology to enhance intercultural and linguistic competencies in language courses; the use of technology in teacher training for administrators and policymakers; and instructional approaches for using technology (i.e., social networking sites, Google Earth) in the classroom. Using these social media and geographical tools, students will expand global awareness in education [24].

The other group of theoretical papers concern virtual language learning. Nowadays AR can cover 31 languages: Spanish, American English, British English, French, German, Portuguese, Italian, Turkish, Russian, Dutch, Danish, Swedish, Norwegian, Arabic, Japanese, Korean, Finnish, Romanian, Hungarian, Czech, Polish, Ukrainian, Bulgarian, Hebrew, Vietnamese, Greek, Indonesian, Afrikaans, Croatian, Farsi, and Hindi. Top 6 most popular programming languages of $\mathrm{AR}$ are: $\mathrm{C} / \mathrm{C}++$, Java, JavaScript, Python, Swift.

Having analyzed the papers relevant for our research we can define the novelty of our paper which is explained by comparison of natural and AR languages as for their degree of compression and special functions; such comparison has not been effected yet.

\section{INTERNET LANGUAGES}

Not regarding languages of programming we focus on special means of communication on the Internet. Leet is a computer language with certain aims and peculiarities. Its appearance dates back to 1990 and its name originated from the word elite. Cambridge dictionary defines it as a way of writing used on the 
internet, in which the usual letters that are used to spell a word are deliberately replaced by numbers or by different characters. It is constructed by means of certain mistakes, usage of numbers instead of letters. The function of it is to decipher the speech content and to leave it within a certain group of users. A peculiar morphological feature of it is the wide usage of certain suffixes, XXor, zor, zorzz, xxorxx among them, age, ness. Free grammar demands more intuition of the speaker than grammar knowledge. The stress is fixed. A lot of rhymes are used to strengthen its expressivity as well as exclamation marks. The following construction is an example of a sentence in leet: $1\left(4 / \varepsilon 7|| /[) 3\left|2574 /[)^{\prime} / 0\right||| 2 \mid 2171 / 9.17^{\prime} 5(0 /|=| \mid 51 / 9\right.$ "I can't understand your writing. It's confusing”. An important specific feature of leet is that it is only a written language which doesn't have an oral form. One can find a leet translator on the Internet urlhttps://md5decrypt.net/en/Leet-translator/ which has translated, for example, the famous phrase To be or not to be as $708302 n 077083$.

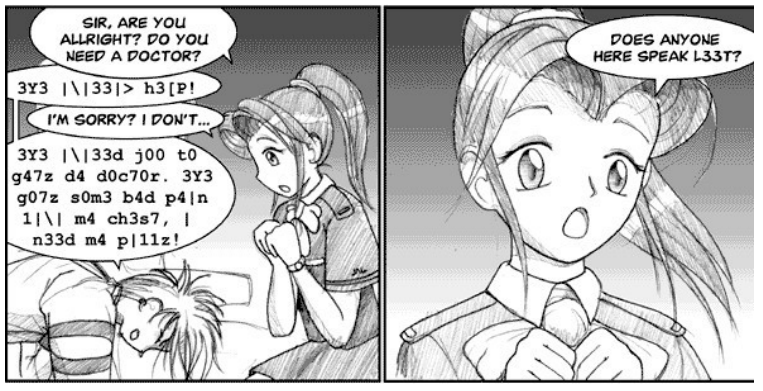

Figure 1 Leetspeak language sample

A popular web comic called Megatokyo brought Leetspeak (L33T) into mainstream. These days, leet speak is very well known to the hardcore Internet community (especially gamers) (Fig. 1).

Chanspeak is the language of 4chan, a website with over 7 million users created in 2003; it is a large-scale, anonymous, and ephemeral community that plays an influential role in Internet culture. Chanspeak shows peculiar in-group misspellings and its main features include shortening, simplifying and cutting down words. On 4chan, several years later, users started to post pictures of catson Saturday, that was renamed 'Caturday'.

Another form of an artificial language is textspeak or SMS language which is defined by Cambridge dictionary as the kind of language and spelling, often containing short forms of words that people use when they are writing text messages. It is considered to be quite annoying for those who are not used to it. Textspeak bears resemblance to standard English, and they can both be considered written languages; however, there are notable structural differences between them. More specifically, Textspeak is characterized by acronyms, the deletion of unnecessary words, vowels, punctuation, and capitalization. This abbreviated written language resembles the early phonological stages of spelling. Early spellers typically omit medial vowels and encode only the salient sounds, (e.g., gd for good) and use letter names to encode whole words (e.g., $r$ for are). Textspeak bears some similarity to early spelling in that it sometimes uses contracted linguistic forms. However, there are many additional features of Textspeak that do not resemble early spelling. For example, Textspeak users often utilize acronyms for popular phrases, such as gtg for got to go, ttyl for talk to you later, etc. This abbreviated Textspeak vocabulary has surfaced in many computer-mediated communication environments, including SMS, instant messaging forums and e-mails. As we mentioned before, the main reason for appearance of this language is the lack of space for rendering a message when one letter or digit can replace a word. As in the previous case it is a written language. To make it more expressive a set of emoticons (symbols representing emotions, e.g., :) for happy), pictograms and logograms are used. The same phrase will look as $2 b$ or not $2 b$.

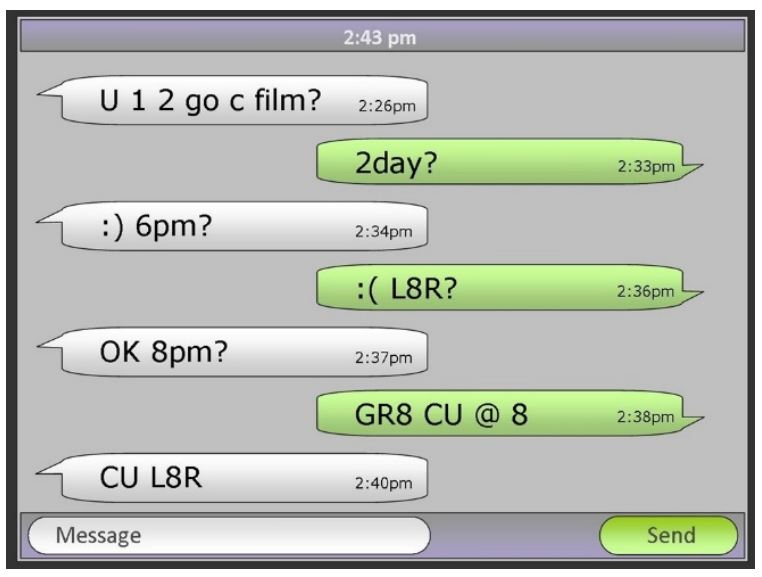

Figure 2 Textspeak language sample

Textspeak is an efficient way to create written messages for informal communication. People use textspeak, not to generate thoughtfulness and literary communication, but to keep in contact and to facilitate communication (Fig. 2). The following text can be interpreted as:
A: You want to go see a film?
B: Today?

A: [Smile] 6 p.m.

B: [Sad] Later? 


\section{A: $O K .8$ p.m.? \\ B: Great, see you at 8.}

\section{A: See you later.}

Mobile slang is based on the function "T9" which is widely used by sending messages from phones. The acronym T9 stands for Text on 9 keys. T9 "predictive texting" is a tool used primarily on non- smart phones (those with just a nine-key keyboard similar to a telephone) to allow users to text more quickly and easily. When certain numbers are entered, T9 looks up words in its fast-access dictionary and displays the word most commonly entered by the user. If a new word is typed that is not in the T9 dictionary, the software adds it to its predictive database so it will be displayed next time. While T9 can learn based on user experiences, it doesn't always correctly guess the word you intend. For example, "4663" could also spell "hood," "home" and "gone." When multiple words can be created by the same numeric sequence, they are called textonyms. Some users while doing it choose the first word suggested by the program. In such case it may happen that the word "book" acquires the meaning "cool".

Written communication in instant messaging, text messaging, chat, and other forms of electronic communication appears to have generated a "new language" of abbreviations, acronyms, word combinations, and punctuation. One of the most interesting and well-known Internet languages is $L O L$ for "laugh out loud" or "lots of love" more emphatic expressions of laughter such as $L M A O$ ("laugh(ing) my ass off"), and ROTFL or ROFL ("roll(ing) on the floor laughing"). Any form of typed text language that is not in proper English is usually in reference to cute cat pictures. The word "Lolcat" is attested as early as June 2006, and the domain name "LOLcats.com" was registered on June 14, 2006. Because LOLspeak started in a written medium, it is difficult to separate out features that we would normally divide into the domains of orthography and phonetics in other phenomena. Indeed, what becomes quite apparent about LOLspeak is that what we might consider to be "phonetic" is often motivated by the orthographic conventions. That the orthography has helped shape this example of language play indicates just how central the written form is to LOLspeak. There is even a Bible translation project going on where they translate the entire Bible into lolspeak. Typical linguistic features are misspelling, defined constant grammar mistakes, limited specific vocabulary. The following picture illustrates all of them (Fig. 3).

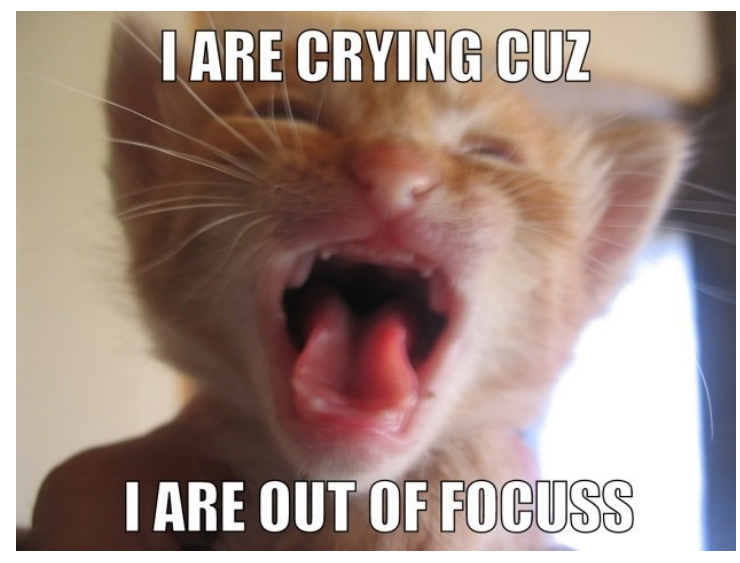

Figure 3 Lolcat language sample

Besides there exist some other Internet languages which are used by a limited audience. For instance they are flaming which refers to the use of rude or profane language in interactions between Internet users; Jejemon used in the Phlippines, sexting which sends sexual messages etc. "Flaming" is defined as hostile and aggressive interactions via text-based computer mediated-communication - have proposed theoretical frameworks to explain possible causes. 'Flaming' as a concept emerged from popular discourse surrounding the online community to describe aggressive, hostile, or profanity- laced interactions via email and in online discussion groups. Commentators expressed concern that this antisocial use of the new technology of the Internet was an indication of the dark side of technology's social effects. The term has evolved in the popular literature so that lay observers commonly represent flaming as a highly negative message that functions like a metaphorical flamethrower that the sender uses to roast the receiver verbally. Jejemon language becomes a form of communication dialect. It was a form of expression used by a particular social group known as Jejemon. However, the Jejemon expression has different formats ranging from basic form of changing letter to number, lowercase letter to uppercase letter, inserting shortcut texts into more complicated format. Jejemon language became popular in 2010 based on the limited space available for text messages. It is primarily composed of alphabet known as Jejebet. It uses Roman alphabet (a-z), Arabic numerals (0-9) and other special characters $(@$, ,!, ,?,.). However, Jejemon word is more than jejebet alphabet. It has several types of pattern namely alternating capitalization, overusage of the letters $\mathrm{H}, \mathrm{X}$ or $\mathrm{Z}$ and mixture of numeric characters and English alphabet. Jejemon language does not follow specific pattern. For example, the phrase "I would like to know more about you, care to tell me your name?" can be translated from English into Jejemon language in several ways: 
i wuD LLyK tO knOw moR3 bOut u. crE 2 t3ll mE yurN@me?

$1 w U D 77 y k+0 k n 0 w$ mUhr3 $4 b 0 U+U, c r+0$ +377 m3 U'r nm3?"

All in all these languages can be united under the common term - creolized texts which means heterogeneous constructions combining natural linguistic units and those ones which are expressed by various means of augmented reality (pictures, figures, sounds, videos etc.).

\section{FUNCTIONS OF INTERNET LANGUAGES IN COMPARISON WITH NATURAL ONES}

To our mind, the combination of natural and artificial languages serves to fulfill the following three functions:

1) compression;

2) expressivity;

3) intimization.
The abundance of information accumulating every day and every hour and the limited volume of a human being attention makes it relevant to present the information in the most concise variant where AR means are of great help. The former telegraph language now has been replaced by various shortenings mentioned above, QR-codes which are ready to unfold the information when necessary etc. Thus, numbers are used to replace letter combinations: $2=$ to; $4=$ for; $8=$ ate, letters replace words: $U=$ you; $C=$ see; $B=$ be; $C U L 8 r=$ see you later; $m s g=$ message; pls = please; $c l d=$ could $;$ gd $=$ good, $k=$ ok; vgd = very good; abt = about; ths = this; asap = as soon as possible; tks = thanks; txt $=$ text; $x=a$ kiss; $T T Y=$ talk to you later, $B T W=$ by the way, IMHO= in my humble opinion, $F Y I=$ for your information, $H A N D=$ have a nice day; rofl = rolling on the floor laughing; imo = in my opinion; $b 4 n=$ bye for now; $b / f$ $=$ boy friend; brb = be right back etc. QR-code, for example, can be used while reading a book and it allows watching a video, a cartoon in addition to a printed text or making acquaintance with an advertisement (Fig. 4).

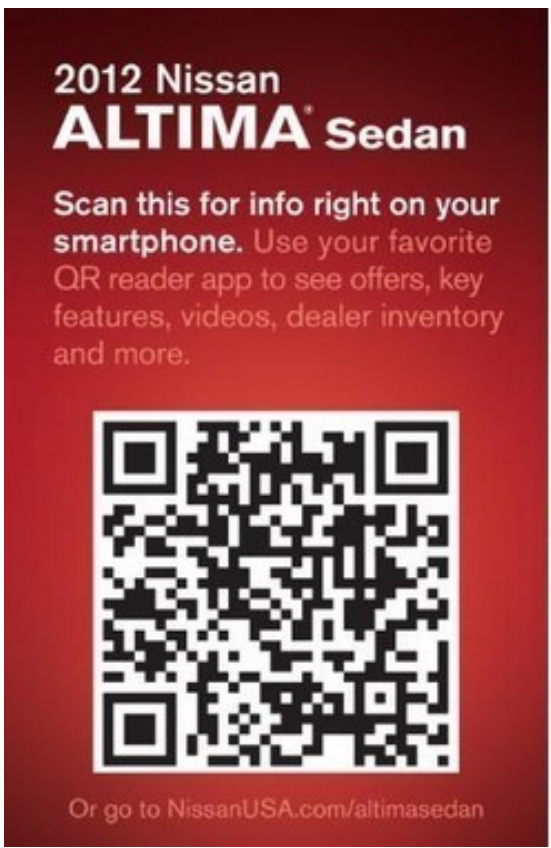

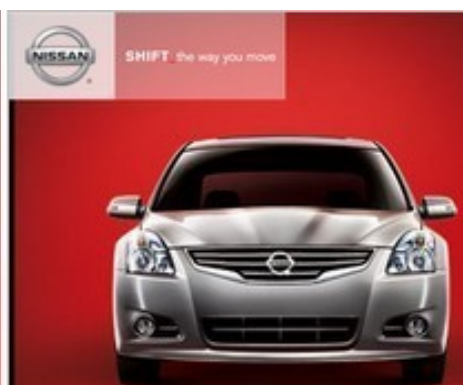

2012 Nissan Altima INNOVATION THAT LASTS

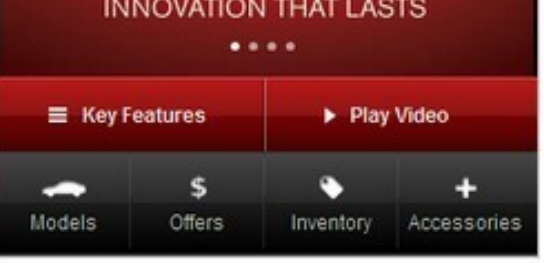

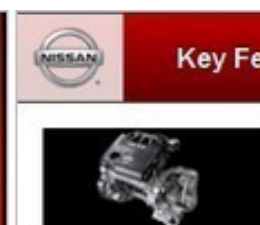

Key Features

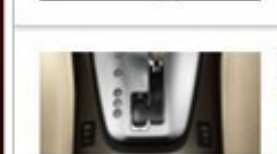

XTRONIC CVTO (CONTINUOUSLY VARIABLE TRANSMISSION]

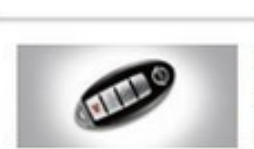

MISSAN INTELLIGENT KEYO WITH PUSH BUTTON IGNITION

Standard on: $2.5 \mathrm{~S}, 3.5$ SR

VIEW INVENTORY
Figure 4 Advertising QR-code.

Augmented reality means in combination with natural language make a text more expressive and interesting for certain readers. LOLspeak is full of funny expressions which quickly penetrate into usual communication, for example with the development of the Ukrainian segment of the Internet, so called "Ukrnet" gains more and more popularity. There are different ways of creating Ukrainian version of the Internet jargon: the translation with the use of emotionally loaded words: Гламурненько
- Файнесенько; Афтар жжот, пеши исчо - Афтор пече, щуо аж хочеться ще; Зочем ви травите? Нащуо ви цьькуєте? Фтему! - Доречно; Классный юзерпик! - Чотке людинозображення! Картинки не грузяиа - Малюнків нема; Плакаль - Рюмсав. During translation the mechanism of associative thinking may work. Association or metaphors can be different and have hint of emotional and humorous colouring: В Бобруйск, жевотное - В Жидачів, тварюко; Ужоснах! - 
Cтрахіттянах! Aфтар, выпей йаду - Афтор, випий тріла;5 баллофф! - 12 балів! Учи албанский! - Вчи москальську, нею Ленін розмовляв! Чмоки, пративный - Цьом, плюгавий; В газенваген! - Та подавіться ви тим газом! Those are few examples of the new born and quite scanty Ukrainian internet slang. As we can see from the information mentioned above, it would be quite hard to translate Lolspeak into Ukrainian slang as the latter has poor vocabulary yet. But we can try to translate and to find Ukrainian analogues to some the most often used Lolspeak phrases: Oh hai - Привid; Ноотіn - Чоловіг; Fursday - Шерстьтвер; KthxbaiДобрпасибай еtc.

Intimization of AR languages (leetspeak for instance) is explained by the desire of certain groups of the Internet users to cipher their message and to hide it from "the aliens". Fig. 5 illustrates this aim of leetspeak - to help "lame" people be in line with other members of the "gang", i.e. join "familiar' people and to exscind those aliens.

\section{What Leetspeak Is}

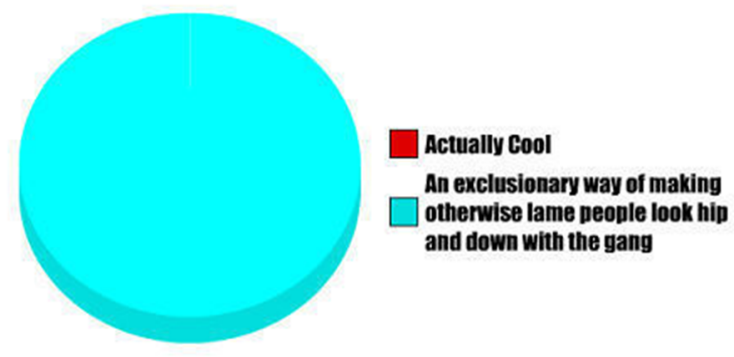

Figure 5 Schematic presentation of leetspeak aim.

\section{CONCLUSIONS}

Answering the question set by us at the beginning of the article as for the improvement of languages we would like to admit that the appearance and functioning of languages of augmented reality have both positive and negative influence on natural languages. Fulfilling 3 main functions (compression, expressivity, intimization) artificial languages developed a set of new linguistic means - a limited list of grammar mistakes and suffixes, typical spelling breaks, reduced punctuation, emoticons. These new means help make texts both of natural and AR languages shorter, more economical and more expressive. But at the same time LOlspeak, leetspeak etc. break grammar and spelling rules discouraging young speakers from acquiring literacy. This mutual interaction is still not fully investigated and analyzed and, moreover, developed. We are confident that it would be a very interesting and useful contribution to the language.

\section{REFERENCES}

[1] E. Klopfer, K. Squire, Environmental detectives the development of an augmented reality plat form for environmental simulations, Educational technology research and development 56 (2008) 203-228. DOI: https://doi.org/10.1007/s11423-0079037-6.

[2] E. Klopfer, J. Sheldon, Augmenting your own reality: Student authoring of science-based augmented reality games, New directions for youth development $2010 \quad$ (2010) 85-94. DOI: https://doi.org/10.1002/ yd.378.

[3] M. Dunleavy, C. Dede, R. Mitchell, Affordances and limitations of immersive participatory augmented reality simulations for teaching and learning, Journal of science Education and Technology 18 (2009) 7-22. DOI: https://doi.org/10.1007/s10956-008-9119-1.

[4] H.-K. Wu, S.W.-Y. Lee, H.-Y. Chang, J.-C. Liang, Current status, opportunities and challenges of augmented reality in education, Computers \& education $62 \quad$ (2013) 41-49. DOI: https://doi.org/10.1016/j. compedu.2012.10.024.

[5] M. Ibanez, D.L. Carlos Delgado Kloos, J.J.G. Rueda, D. Maroto, Learning a foreign language in a mixed-reality environment, IEEE Internet Computing 15 (2011) 44-47. DOI: https://doi.org/10.1109/MIC. 2011.78.

[6] E. Solak, R. Cakir, Exploring the effect of materials designed with augmented reality on language learners' vocabulary learning, Journal of Educators Online 12 (2015) 50-72.

[7] M. Akcayır, G. Akcayır, Advantages and challenges associated with augmented reality for education: A systematic review of the literature, Educational Research Review 20 (2017) 1-11. DOI: https://doi.org/10.1016/j.edurev.2016.11.002.

[8] A. Di Serio, M. B. Ibanez, C. D. Kloos, Impact of an augmented reality system on students' motivation for a visual art course, Computers \& Education 68 (2013) 586-596. DOI: https://doi.org/10.1016/j. compedu.2012.03.002.

[9] K. Lee, Augmented reality in education and training, TechTrends 56 (2012) 13-21. DOI: https://doi.org/10.1007/s11528-012-0559-3.

[10] E. Bonner, H. Reinders, Augmented and virtual reality in the language classroom: Practical ideas, Teaching English with Technology 18 (2018) 3353. 
[11] M.E.C. Santos, T. Taketomi, G. Yamamoto, M.M.T. Rodrigo, C. Sandor, H. Kato, Augmented reality as multimedia: the case for situated vocabulary learning, Research and Practice in Technology Enhanced Learning 11 (2016) 1-23. DOI: https://doi.org/10.1186/s41039-016-0028-2.

[12] S. Symonenko, N. Zaitseva, V. Osadchyi, K. Osadcha, E. Shmeltser, Virtual reality in foreign language training at higher educational institutions, CEUR Workshop Proceedings 2547 (2019) 37-49.

[13] R.O. Tarasenko, S.M. Amelina, Y.M. Kazhan, O.V. Bondarenko, The use of AR elements in the study of foreign languages at the university, CEUR Workshop Proceedings 2731 (2020) 129-142.

[14] J.S. Beaudin, S.S. Intille, E.M. Tapia, R. Rockinson, M.E. Morrisc, Context-sensitive microlearning of foreign language vocabulary on a mobile device, in: Lecture Notes in Computer Science, volume 4794 of AmI '07, Springer, ACM Press, 2007. DOI: https://doi.org/10.1007/978-3-540-76652-0_4.

[15] B. Perry, Gamifying French language learning: a case study examining a quest-based, augmented reality mobile learning-tool, Procedia - Social and Behavioral Sciences 174 (2015) 2308-2315. DOI: https://doi.org/10.1016/j.sbspro.2015.01.892.

[16] Y.-F. Yang, Engaging students in an online situated language learning environment, Computer Assisted Language Learning 24 (2011) 181-198. DOI: https://doi.org/10.1080/09588221.2010.538700.

[17] R. Godwin-Jones, Augmented reality and language learning: From annotated vocabulary to place-based mobile games, Language Learning \& Technology 20 (2016) 9-19.

[18] M. Bower, N.M. Cathie Howe, A. Robinson, D. Grover, Augmented reality in education - cases, places and potentials, Educational Media International $51 \quad$ (2014) 1-15. DOI: https://doi.org/10.1080/09523987. 2014.889400.

[19] M. Slussareff, P. Boha'c čkova', Students as game designers vs. 'just' players: Comparison of two different approaches to location-based games implementation into school curricula, Digital Education Review (2016) 284-297. DOI: https://doi.org/10.1344/der.2016.29.284-297.

[20] I. Radu, Augmented reality in education: a metareview and cross-media analysis, Personal and Ubiquitous Computing 18 (2014) 1533-1543. DOI: https://doi.org/10.1007/s00779-013-0747-y.

[21] E. Yeh, G. Kessler, Enhancing linguistic and intercultural competencies through the use of social network sites and google earth, in: Promoting global literacy skills through technology-infused teaching and learning, IGI Global, 2015, pp. 1-22. DOI: https://doi.org/10.4018/978-1-4666-6347-3.ch001.

[22] E. Hawkinson, Augmented reality enhanced materials design for language learning, in: The Asian Conference on Technology in the Classroom, Conference Proceedings 2014, 2014, pp. 155-161.

[23] R. Valle, Teaching with augmented reality is here, 2014.

[24] D. Crystal, 2b or not 2b, The Guardian 5 (2008). 